\title{
Exon 12 Ceruloplasmin Gene New Nonsense Mutation Causing Aceruloplasminemia in an Italian Patient
}

\author{
Giuseppina Calvaruso, Maria Concetta Renda*, Disma Renda, Emanuela Fecarotta, \\ Angela Piazza, Antonino Giangreco, Aurelio Maggio \\ UOC Ematologia per le Malattie Rare del Sangue e degli Organi Ematopoietici, AOR Villa Sofia-Cervello, \\ Palermo, Italy \\ Email: *renda.mc@gmail.com
}

Received 20 February 2016; accepted 22 March 2016; published 25 March 2016

Copyright (C) 2016 by authors and Scientific Research Publishing Inc.

This work is licensed under the Creative Commons Attribution International License (CC BY).

http://creativecommons.org/licenses/by/4.0/

c) (†) Open Access

\begin{abstract}
Hereditary aceruloplasminemia is a rare disease characterized by iron overload and neurodegeneration. Aceruloplasminemia is due to the absence/deficiency of ceruloplasmin, responsible for iron overload in liver, pancreas and other organs. We report the case of an Italian patient with hyperferritinemia, diabetes and hepatic iron excess, suspected to be affected by aceruloplasminemia. Patient underwent brain magnetic resonance imaging with and without paramagnetic medium contrast, which showed a hypointesity due to iron storage. The presence of a neurological disease and iron storage in the brain has led to assume the suspect of the aceruloplasminemia disease. We confirmed this hypothesis by the identification of a new nonsense mutation in exon 12 ceruloplasmin gene at codon 748 , in homozygous status. When the diagnosis of ACP was established, the patient started chelation therapy with $75 \mathrm{mg} / \mathrm{Kg} /$ day deferiprone (DFP). Two months of starting therapy with DFP, serum ferritin values decreased to $693 \mathrm{ng} / \mathrm{ml}$; the patient well tolerated the drug, and there have been no adverse events. Although rare, aceruloplasminemia should be considered in the differential diagnosis of unexplained iron overload.
\end{abstract}

\section{Keywords}

Aceruloplasminemia, Brain, Copper, Diabetes, Ferritin

\section{Introduction}

Hereditary aceruloplasminemia (ACP) is a rare autosomal recessive disease characterized by iron overload and

${ }^{*}$ Corresponding author.

How to cite this paper: Calvaruso, G., Renda, M.C., Renda, D., Fecarotta, E., Piazza, A., Giangreco, A. and Maggio, A. (2016) Exon 12 Ceruloplasmin Gene New Nonsense Mutation Causing Aceruloplasminemia in an Italian Patient. Open Journal of Internal Medicine, 6, 20-25. http://dx.doi.org/10.4236/ojim.2016.61005 
progressive neurodegeneration. In ACP there is a complete absence of ceruloplasmin (CP), a copper-containing ferroxidase which oxidizes the iron from ferric to ferrous ion, a needed change for the incorporation of iron into transferrin.

Thus, the absence or deficiency of $\mathrm{CP}$ is responsible for iron accumulation in liver, pancreas and other organs, despite normal levels of serum transferrin saturation. Patients affected by ACP develop diabetes mellitus, retinal degeneration, ataxia and neurodegeneration, which, in the late stage of life, can evolve into dementia [1].

The CP gene is located on short arm of chromosome 3, consisting of 19 exons and encoding a $130 \mathrm{KD}$ protein (GENEATLAS). ACP is rare in whites and it has been described mainly in Asians [2].

Here we report the case of 43-year-old male Italian patient, homozygous for a nonsense mutation in the exon 12 of $\mathrm{CP}$ gene at codon 748 , causing a premature truncation of the $\mathrm{CP}$ protein synthesis.

\section{Material and Methods}

\subsection{MRI, Biochemical Analysis and Liver Biopsy Processing}

Spinal cord and brain MRI was performed with and without paramagnetic medium contrast.

LIC and copper concentrations were determined both by atomic spectrophotometry and Perl's staining on liver biopsy samples and Ferriscan.

Biochemical determinations of ceruloplasmin, ferritin and transferrin levels were performed by standard procedures [3].

\subsection{Genetic Analysis}

HFE and CP genes were investigated by direct genomic sequencing of coding regions. Specific Polymerase Chain Reactions (PCR) and direct sequencing primers for CP and HFE genes were designed in our laboratory on the basis of sequence databases (GENATLAS; HGNC 2295 for CP gene and HCGN 4886 for HFE gene) (http://www.ncbi.nlm.nih.gov/pubmed).

Having obtained the informed consent for molecular studies according to institutional guidelines, genomic DNA was extracted from peripheral blood mononuclear cells by means of SDS - phenol/chloroform extraction. PCRs were carried out on genomic DNAs in a thermal cycler using $10 \mathrm{mM}$ each primers and $0.5 \mathrm{U}$ Taq polymerase in a final volume of $50 \mu$ l. Direct sequencing was performed, using a Genome Lab Quick Start Kit for Dye Terminator Cycle Sequencing (Beckman), in the Genetic Analysis System CEQ8800 Beckman Coulter.

As controls for the CP and HFE genes, DNAs from apparently healthy individuals with iron and copper normal parameters were analyzed.

\section{Results}

\subsection{Case Report}

A 43-year-old male Italian patient, in March 2013, was admitted to our hospital because of his poor hyperferritinemia control. Moreover the patients showed a known insulin-dependent diabetes mellitus, developed at age 25 , and hypercholesterolemia.

In 2002, hyperferritinemia was found following a family screening for diagnosis of hemochromatosis to his brother.

In the same year, in a different hospital, the patient was diagnosed hereditary hemochromatosis.

Indeed, although liver function tests were normal, ultrasound (US) evaluation of liver and spleen did not show morphologic or structural alterations and the transferrin saturation index was normal, liver biopsy, performed to complete the liver diagnostic evaluation, showed portal fibrosis. Liver iron concentration (LIC) was $11,320 \mu \mathrm{g} / \mathrm{g}$ dry weights and Perl's staining showed severe haemosiderosis homogeneously distributed in lobule hepatocytes and Kupffer cells. Serum ferritin level exceeded $2000 \mathrm{ng} / \mathrm{ml}$.

From 2002 to 2011 , the patient underwent a phlebotomy every 45 days up to anemia.

In January 2010 the patient was hospitalized for stroke. Brain magnetic resonance imaging (MRI) performed by means of paramagnetic contrast showed a left paramedian pontine lacunar ischemic.

In January 2013, due to the presence of neurological events (upper and lower limb cramps, impaired balance and memory) the patient has undergone spinal cord and brain MRI. 
Brain T2-weighted MRI showed a hypointesity consistent with paramagnetic effect, due to iron storage in the basal ganglia (Figure 1). The patient has come to our attention in March 2013.

The presence of hyperferritinemia, hypochromic microcytic anemia, juvenile diabetes, and evidence of iron stores in the central nervous system (CNS), the latter absent in primary and secondary hemochromatosis, placed the suspicion of ACP.

Indeed, iron deposits in the central nervous system are critical to differential diagnosis between hemochromatosis and ACP [4]. Biochemical determinations revealed undetectable ceruloplasmin and low copper levels (8 $\mu \mathrm{g} / \mathrm{dl}$, range $70-140 \mu \mathrm{g} / \mathrm{dl})$.

The evaluation of intrahepatic iron storages, performed by Ferriscan (R2), showed a LIC of $11.8 \mathrm{mg} / \mathrm{g}$ of dry tissue. Ophthalmic investigation revealed retinal degeneration without apparent visual impairment. Based on all these data, the patient was diagnosed ACP.

The clinical diagnosis of aceruloplasminemia was confirmed by genetic analysis of the $\mathrm{CP}$ gene

When the diagnosis of ACP was established, the patient started chelation therapy with $75 \mathrm{mg} / \mathrm{Kg} /$ day deferiprone (DFP). Laboratory findings on admission and after two months chelating therapy are showed on Table 1.

Two months of starting therapy with DFP, serum ferritin values decreased to $693 \mathrm{ng} / \mathrm{ml}$; the patient well tolerated the drug, and there have been no adverse events (Table 1).

\subsection{Genetic Analysis}

Sequence analysis of the patient whole CP gene revealed the presence of a homozygous C-T transversion at codon 748 in exon 12, causing a nonsense glutamine $(\mathrm{Q}) \rightarrow$ stop codon $(\mathrm{X})$ substitution (CAA $\rightarrow$ TAA; Q748X) (Figure 1(a)).

The genomic sequencing of HFE coding regions showed a heterozygous allele for the H63D variant.

\section{Discussion}

Hereditary aceruloplasminemia is a rare iron metabolic disorder characterized by iron overload and neurodegeneration; it is due to the absence/deficiency of ceruloplasmin, responsible for iron overload in liver, pancreas and other organs.

The first clinical manifestation of aceruloplasminemia is diabetes resulted by pancreatic involvement.

Table 1. Patient laboratory findings on admission [1] and after two months chelating therapy [2].

\begin{tabular}{cccc}
\hline Findings & $\mathbf{1}$ & $\mathbf{2}$ & Normal Standard \\
\hline $\mathrm{RBC}\left(\times 10^{6} / \mathrm{ul}\right)$ & 6.01 & 5.58 & $4.50-5.50$ \\
$\mathrm{Hb}(\mathrm{g} / \mathrm{dL})$ & 12.0 & 12.3 & $13.5-17.0$ \\
$\mathrm{Hct}(\%)$ & 37.7 & 37.3 & $40.0-50.0$ \\
$\mathrm{MCV}(\mathrm{fL})$ & 63 & 64.5 & $79.0-96.0$ \\
$\mathrm{MCH}(\mathrm{pg})$ & 20.0 & 21.3 & $27.0-33.0$ \\
$\mathrm{MCHC}(\mathrm{g} / \mathrm{dL})$ & 31.9 & 33.1 & $31.0-36.0$ \\
$\mathrm{Ret}(\%)$ & 18.9 & 18.1 & $0.5-2.5$ \\
$\mathrm{Cu}(\mu \mathrm{g} / \mathrm{dL})$ & 8.7 & 8.0 & $70-140$ \\
Glycemia $(\mathrm{mg} / \mathrm{dl})$ & 342 & 189 & $74-118$ \\
$\mathrm{AST}(\mathrm{IU} / \mathrm{L})$ & 23 & 20 & $10-40$ \\
ALT $(\mathrm{IU} / \mathrm{L})$ & 38 & 32 & $5-40$ \\
Iron level $(\mathrm{mg} / \mathrm{dL})$ & 36 & 65 & $45-182$ \\
Ferritin (ng/mL) & 1017.5 & 693.1 & $23.9-336$ \\
Transferrin $(\mathrm{mg} / \mathrm{dl})$ & 212 & 194 & $180-329$ \\
Transferrin saturation $(\%)$ & 13.6 & 26.8 & $20-45$ \\
Ceruloplasmin (mg/dL) & 0 & 0 & $20-60$ \\
\hline
\end{tabular}

RBC: red blood cells; Hb: hemoglobin; Hct: hematocrit; MCV means corpuscular volume; MCH means corpuscular hemoglobin; MCHC means corpuscular hemoglobin concentration; Ret: reticulocytes; $\mathrm{Cu}$ : copper; AST: aspartate aminotransferase; ALT: alanine aminotransferase. 
(a)

210

220

230

A A T G G GA T T A T T C C C C A TA A G G G A T G GGA A

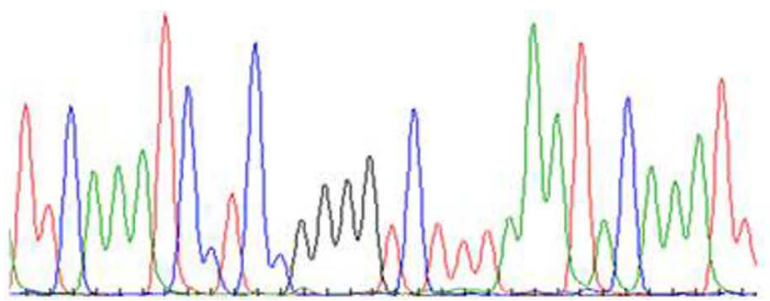

(b)

220

230

240

A A T G GGA T TA T T C CC C A CAA G G GA G T G GGA

Figure 1. Genomic Sequencing of Exon 12 CP Gene Q748X DNA variant, CAA > TAA. (a) Patient homozygous mutant; (b) Normal control wild type. Patient has released an informed consent by which would agree that biological material of his person was stored in the Laboratory of UOC Hematology for Rare Diseases of Blood and Hematopoietic Organs of AOR Villa Sofia-Cervello-Palermo and used, with guarantee of strict confidence, for further studies or research of genetic/clinical interest.

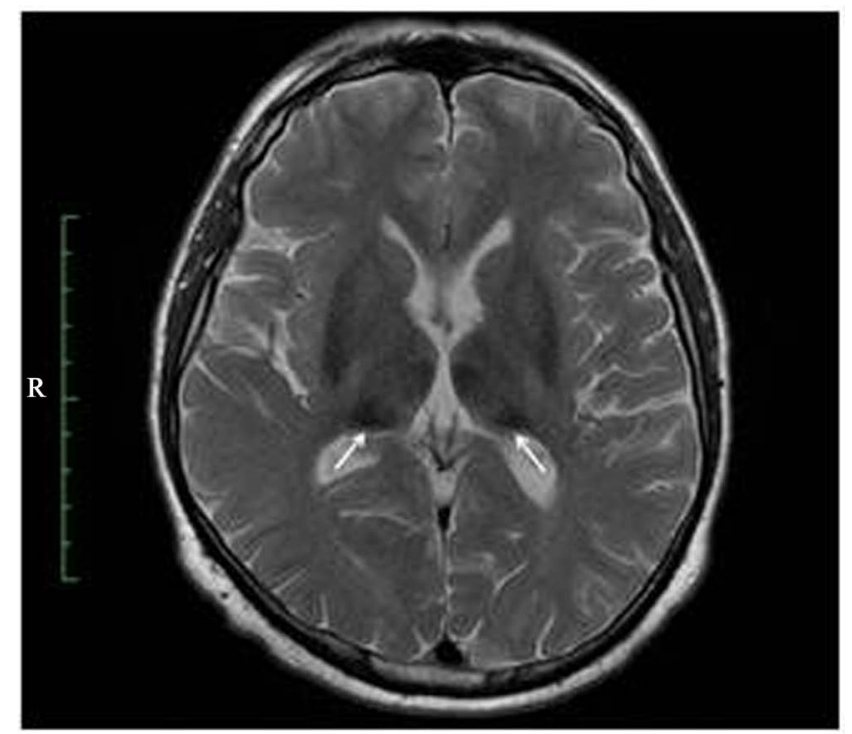

Figure 2. Brain MRI performed by means of paramagnetic contrast : hypo-intensities in the basal ganglia (arrowheads).

Neurological disease occurs few years after onset, and it is characterized by focal dystonia, dysarthria, extrapyramidal signs (bradykinesia, rigidity), cerebellar ataxia, and dementia. Moreover, retinal pigmentary degeneration with less clinical impact is present.

A constant clinical manifestation is a moderate/severe anemia with high levels of serum ferritin and low levels of serum iron and transferrin saturation [1] [4].

Here we described a case of aceruloplasminemia, in a patient found to be homozygous for a new nonsense mutation in the CP gene. The Q748X mutation, identified in exon 12 of CP gene, causes a stop codon at position 748, which subsequently produced a truncated CP protein lacking 309 amino acids.

In the case reported, the diagnosis of ACP was placed several years after the detection of hyperferritinemia, and the diagnostic clue has been provided by the brain T2-weighted MR imaging performed to establish the causes underlying neurological symptoms (Figure 2).

$\mathrm{CP}$ is expressed in the central nervous system as well as in visceral organs and it plays an important role in the brain iron transport and storage and it is essential for neuron survival in CNS [2].

In ACP the failure of apoceruloplasmin synthesis determines a deficiency of ceruloplasmin, but it does not affect the copper metabolism [5]. 
As in other cases of ACP reported in the literature [6] [7], our patient presented a moderate degree of anemia, associated with low serum iron and high serum ferritin. These features are typical of aceruloplasminemia and antecedent to the development of neurological symptoms.

In order to limit the development of hepatic and neurological lesions, as well as the aggravation of diabetes related to iron toxicity, during the past years several therapeutic options have been reported, followed by different and not always effective outcomes.

In patients with ACP, conventional phlebotomy treatment was not found to be effective in removing iron cerebral stores; moreover, the presence of anemia, makes it difficult to practice phlebotomy [8].

It was reported that oxidative stress represents the primary cellular cytotoxic process, playing a pivotal role in the central nervous system damage in ACP [9].

If oxidative stress is one of the major causes of cell damage in ACP, a possible way to treat it may be to reduce oxidative stress using a drug such as DFP [10].

The DFP chemically behaves as an antioxidant. It is a molecule able to bind the iron in a molar ratio of 3:1, and to ensure a good permeability to drug of mitochondrial membranes and blood-brain barrier [11].

Our patient underwent a treatment with $75 \mathrm{mg} / \mathrm{Kg} /$ day DFP, and two months of starting therapy, serum ferritin values decreased to $693 \mathrm{ng} / \mathrm{ml}$. DFP therapy was well tolerated and without adverse events.

\section{Conclusions}

Because of the difficulty of recovering neurological damages, the dosage of serum copper and CP may be useful in early diagnosis of ACP in patients with elevated serum ferritin values and microcytic hypochromic anemia, especially in patients with insulin-dependent diabetes [6] [7].

Although ACP is a quite rare disease in Caucasian population, it should be included as differential diagnosis in presence of juvenile-onset diabetes, moderate anemia and high serum ferritin levels unrelated to chronic diseases.

Moreover, in ACP an early diagnosis and an effective treatment of iron overload with iron chelators is critical in order to prevent the onset of organ damages and the disease progression, especially the neurological damage.

\section{Acknowledgements}

We thank Prof. Aurelio Maggio for the clinical advice, for the scientific support and for the continuous encouragement to deal new challenges.

\section{References}

[1] Hiroaki, M. (2015) Aceruloplasminemia. Neuropathology, 35, 83-90. http://dx.doi.org/10.1111/neup.12149

[2] Yang, F., Naylor, S.L., Lum, J.B., Cutshaw, S., McCombs, J.L., Naberhau, S.K.H., McGill, J.R., Adrian, G.S., Moore, C.M., Barnett, D.R. and Bowman, B.H. (1986) Characterization, Mapping, and Expression of the Human Ceruloplasmin Gene (Intragenic Triplication/Dissimilar cDNAs/Human Chromosome3/Lymphocyte Expression/DNA Polymorphisms). Proceedings of the National Academy of Sciences of the United States of America, 83, 3257-3261. http://dx.doi.org/10.1073/pnas.83.10.3257

[3] Giambattistelli, F., Bucossi, S., Salustri, C., Panetta, V., Mariani, S., Siotto, M., Ventriglia, M., Vernieri, F., Dell' Acqua, M.L., Cassetta, E., Rossini, P.M. and Squitti, R. (2012) Effects of Hemochromatosis and Transferrin Gene Mutations on Iron Dyshomeostasis, Liver Dysfunction and on the Risk of Alzheimer's Disease. Neurobiology of Aging, 33, 1633-1641. http://dx.doi.org/10.1016/j.neurobiolaging.2011.03.005

[4] Kono, S. and Miyajima, H. (2006) Molecular and Pathological Basis of Aceruloplasminemia. Biological Research, 39, 15-23. http://dx.doi.org/10.4067/S0716-97602006000100003

[5] Klomp, L.W.J. and Gitlin, J.D. (1996) Expression of the Ceruloplasmin Gene in the Human Retina and Brain: Implications for a Pathogenetic Model in Aceruloplasminemia. Human Molecular Genetics, 5, 1989-1996. http://dx.doi.org/10.1093/hmg/5.12.1989

[6] Ogimoto, M., Anzai, K., Takenoshita, H., Kogawa, K., Akehi, Y., Yoshida, R., Nakano, M., Yoshida, K. and Ono, J. (2011) Criteria for Early Identification of Aceruloplasminemia. Internal Medicine, 50, 1415-1418. http://dx.doi.org/10.2169/internalmedicine.50.5108

[7] Hatanaka, Y., Okano, T., Oda, K., Yamamoto, K. and Yoshida, K. (2003) Aceruloplasminemia with Juvenile-Onset Diabetes Mellitus Caused by Exon Skipping in the Ceruloplasmin Gene. Internal Medicine, 42, 599-604. 
http://dx.doi.org/10.2169/internalmedicine.42.599

[8] Xu, X., Pin, S., Gathinji, M., Fuchs, R. and Harris, Z.L. (2002) Acerulospasminemia: An Inherited Neurodegenerative Disease with Impairment of Iron Homeostasis. Annals of the New York Academy of Sciences, 1012, 299-305. http://dx.doi.org/10.1196/annals.1306.024

[9] Gonzalez-Cuyar, L.F., Perry, G., Miyajima, H., Atwood, C.S., Riveros-Angel, M., Lyons, P.F., Siedlak, S.L., Smith, M.A. and Castellani, R.J. (2008) Redox Active Iron Accumulation in Aceruloplasminemia. Neuropathology, 28, 466471. http://dx.doi.org/10.1111/j.1440-1789.2008.00901.x

[10] Sohn, Y.S., Breuer, W., Munnich, A. and Cabantchik, Z.I. (2008) Redistribution of Accumulated Cell Iron: A Modality of Chelation with Therapeutic Implications. Blood, 111, 1690-1699. http://dx.doi.org/10.1182/blood-2007-07-102335

[11] Fredenburg, A.M., Sethi, R.K., Allen, D.D. and Yokel, R.A. (1996) The Pharmacokinetics and Blood-Brain Barrier Permeation of the Chelators 1,2 Dimethly-, 1,2 Diethyl-, and 1-[Ethan-1'ol]-2-Methyl-3-Hydroxypyridin-4-One in the Rat. Toxicology, 108, 191-199. http://dx.doi.org/10.1016/0300-483X(95)03301-U 